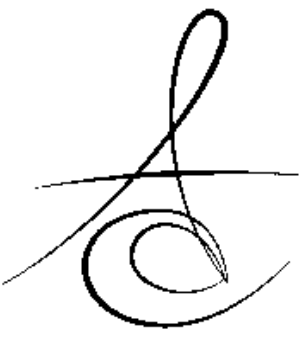

\title{
AKIŞKAN ÖZELLİKLİ İKİ RESTORATİF MATERYALİN LED IŞIK KAYNAĞI İLE POLIMMERİZASYONU SIRASINDA OLUŞAN ISI DEĞİŞİMİNİN KARŞILAŞTIRILMASI
}

\section{COMPARISON OF TEMPERATURE CHANGE IN TWO FLOWABLE RESTORATIVE MATERIALS DURING POLYMERIZATION WITH LED LIGHT CURING UNIT ${ }^{*}$}

\author{
Dr. Öğr. Üyesi Didem ÖNER ÖZDAş* \\ Dr. Öğr. Üyesi Sevgi ZORLU* \\ Dr. Öğr. Üyesi Pınar Kıymet KARATABAN*
}

Makale Kodu/Article code: 3352

Makale Gönderilme tarihi: 12.02 .2017

Kabul Tarihi: 18.12.2017

\section{Öz}

Amaç: Rezin bazlı dental restoratif materyallerin ışık kaynağıyla polimerizasyonları sırasında ortaya çıkan ısının pulpaya biyolojik zarar verebileceği çeşitli çalışmalarda araştırılmıştır. Bu in vitro çalışmanın amacı iki farklı LED ışık kaynağı kullanarak düşük viskoziteli farklı iki restoratif materyalin polimerizasyonu sırasında ortaya çıkan ISI değişikliğinin belirlenerek karşılaştırılmasıdır.

Gereç ve Yöntem: İki farklı akışkan kompozit restorasyon materyali; Filtek-Ultimate Akışkan(3M ESPE, St Paul, MN, USA) ve SDR; Smart Dentin Replacement Material(Dentsply Caulk, Milford, DE, USA) iki farklı LED ışık kaynağı; EliparS10(3M ESPE, St Paul, MN, USA) ve WoodPecker-LEDB(Keju Med.Prod.Foshan,China) ile polimerize edilerek oluşan ISı değişimleri kaydedilmiştir. Çalışmada restoratif materyaller, $10 \mathrm{~mm}$ çapında, $2 \mathrm{~mm}$ yüksekliğinde teflon kalıplara yerleştirilmiş ve başlangıçtan itibaren ışık ile polimerizasyonları sırasında meydana gelen ISı değişimleri teflon kalıbın tabanına yerleştirilmiş, kompüterize dijital termometre ile ölçülerek kaydedilmiştir. Toplam 80 örnek üzerinden 320 ISI ölçümü gerçekleştirilmiştir. İstatistiksel analizler IBM SPSS Statistics22 programı kullanarak yapılmıştır.

Bulgular: Filtek-Ultimate akışkan kompozit restoratif materyalinin Elipar Led ışık kaynağı ile polimerizasyonu sırasında ortaya çıkan ıSı farkı ortalamaları Woodpecker Led ışık kaynağı ile meydana gelen ıSı farkı ortalamalarından anlamlı derecede yüksek bulunmuştur $(19,07 \pm 2,52-\quad 12,79 \pm 1,61)$. Benzer şekilde SDR-Elipar başlangıç-ISı farkı ortalaması SDR-Woodpecker başlangıçISI farkı ortalamasından anlamlı derecede yüksek bulunmuştur $(15,95 \pm 0,97-14,08 \pm 1,18)$. İki restoratif materyalin karşılaştırması yapıldığında ise, Filtek-Ultimate-Elipar ISI farkı SDR-Elipar ISI farkı ortalamasından anlamlı derecede yüksek bulunmuştur.

Sonuç: Her iki ışık kaynağı ile de viskositeleri düşük olan iki dolgu materyalinin polimerizasyonu esnasında oluşan ISı farkı ortalaması $5.5^{\circ} \mathrm{C}$ den fazladır. Pulpaya yakın, derin kavitelerde akışkan restoratif materyallerin kullanılmasının pulpada geri dönüşümsüz hasar bırakabileceği gözönünde bulundurulmalıdır.

Anahtar Kelimeler: Dental ışık kaynağı, rezin kompozitler, foto-aktivasyon, polimerizasyon, ISı artışı

\section{ABSTRACT}

Aim: As it was previously reported, the heat generated during polymerization of the resin based dental restorative materials may cause harmful biological effects on pulpal tissue. The aim of this in-vitro study was to measure and compare the increase in temperature of two different flowable dental restorative materials during polymerization with two different LED-Light curing units. Materials and Methods: Two low-viscosity resin based composites; Filtek-Ultimate Flow(3M-ESPE, StPaul, MN, USA) and SDR; Smart Dentin Replacement(DentsplyCaulk,Milford,DE,USA) were photo-activated with two different LED-Light curing units; EliparS10(3M-ESPE, StPaul,MN,USA) and WoodPecker-LEDB(Keju Med. Prod., Foshan, China) and the change in temperature was recorded during the polymerization process.

Restorative materials were placed into a Teflon mould with a cylindrical opening $10 \mathrm{~mm}$ in diameter and $2 \mathrm{~mm}$ in height and the change in temperature during light curing was recorded with a thermal probe connected to a digital precision thermometer. 320 recordings were done out of 80 specimens. Statistical data analysis was made using IBM SPSS Statistics22 Programme.

Results: The mean temperature increase of FiltekUltimate Flow during light curing with Elipar(3M ESPE) was significantly higher than with WoodPecker $(19,07 \pm$ 2,52- 12,79 $\pm 1,61)$. Likewise, the mean temperature increase of SDR during light curing with Elipar(3M ESPE) was significantly higher than with Woodpecker $(15,95 \pm 0,97-14,08 \pm 1,18)$. Comparing the two restorative materials, the mean temperature increase of FiltekUltimate Flow was significantly higher than SDR while curing with Elipar.

Conclusion: The mean temperature increase in both restorative materials during polymerization with either LED-light curing units were higher than that of $5.5{ }^{\circ} \mathrm{C}$. Low-viscosity restorative materials should be considered carefully within profound cavities as they may cause irreversible harmful effects to dental pulp during polymerization.

Keywords: Dental light curing units, resin composites, photo-activation, polymerization, temperature increase

*İstanbul Aydın Üniversitesi, Diş Hekimliği Fakültesi, Pedodonti AD, İstanbul

* Çalışmanın bir bölümü 26-28 Ekim 2016 tarihinde IMSEC- International Science and Engineering

Congress'de sözlü bildiri olarak sunulmuştur.

$\checkmark$ Çalışma için herhangi bir kurum ya da kuruluştan destek alınmamıştır. 
Atatürk Üniv. Diş Hek. Fak. Derg.

J Dent Fac Atatürk Uni

Cilt:28, Sayı:4, Yıl: 2018, Sayfa, 482-486
ÖNER ÖZDAŞ ,ZORLU

KARATABAN

\section{GİRIŞ}

Dental restoratif materyallerin gelişimi sürecinde kavite preperasyon tekniklerinin değişmesi, restorasyon materyallerinin çeşitlenmesi ve estetik diş hekimliğine talebin artmasıyla da ışık ile polimerize olan materyaller etkin ve vazgeçilmez hale gelmiştir. Işık kaynakları, ışığa duyarlı restoratif materyaller, rezin kompozitler, rezin modifiye cam iyonomerler, poliasit modifiye rezin kompozitler, pit ve fissür örtücüler, bağlayıcı ajanlar, periodontal materyaller, yapıştırıcı ajanlar ve geçici restoratif materyallerin polimerize edilmesinde kullanılmaktadırlar ${ }^{1-4}$. Günümüzde polimerizasyon kaynakları olarak halojen lambalar, ışık yayan diyotlar, plazma ark lambalar ve argon iyonu lazerleri kullanılmaktadır.

Kuartz-tungsten-halojen ışık kaynakları; Rezin bazlı kompozitlerin polimerizasyonunda yaygın olarak kullanılmaktadır. Tipik olarak ışık şiddeti 400-800 mW/ $\mathrm{cm}^{2}$ dir. Kompozit rezinleri $2 \mathrm{~mm}$ derinliğe kadar $40 \mathrm{sn}$ süre ile uygulandığında polimerize etmektedir ${ }^{5,6}$.

LED ışık kaynakları; Halojen ışık kaynaklarında karşılaşılan sorunları bertaraf etmek için ışık yayan diyot (Ligth Emitting Diode, LED) teknolojisi kullanılmaya başlanmıştır. LED Işık kaynakları dar bir spektral aralıkta ışık oluşturdukları için daha az güce ihtiyaç duymaktadırlar. Böylece soğutucu fana gerek duymadıkları gibi şarj edilebilen aletler oldukları için daha hafiftirler. Ömürleri 10.000 saat civarındadır. Sabit şiddette ışık üretirler(700-1200 mW/cm²). Daha az ISI üretirler. Pek çok çalışmada halojen ışık kaynaklarından daha üstün oldukları belirtilmektedir.

Plazma ark ışık kaynakları; Daha kısa sürede, daha etkili polimerizasyon sağlamak amacıyla üretilmiş ışık kaynaklarıdır. Ancak polimerizasyon hızlı olduğu için, polimerizasyon büzülmesi miktarı da yüksektir.

Lazer ışık kaynakları; Uzun süredir bilinmelerine karşın ekonomik nedenler dolayısıyla kullanım alanı sınırlı kalmıştır. Argon iyonu lazeri farklı frekanslarda ışık yayarken, mavi lazerler rezin bazlı kompozitlerin polimerizasyonunda kullanılmaktadır ${ }^{1,6}$.

Dental materyallerin polimerizasyonu, uygun fiziksel özellikleri ve tatminkar klinik performansı elde etmede büyük önem taşımaktadır. Yetersiz polimerizasyon durumunda materyalin su emilimi ve çözünürlüğü artacak ve bunun sonucunda fiziksel özellikleri ortalamanın altında bir performans sergileyecektir ${ }^{7,8,19}$.

Dişin tedavisi esnasında yapılan tedavinin türüne bağlı olarak hem diş yüzeyinde hem de pulpada
ISı artışı olmaktadır. Dişe dışarıdan uygulanan ISI, şiddetine ve süresine bağlı olarak, pulpada farklı düzeylerde travmaya neden olabilir. Pulpada ıSı artışı; dişin hazırlanması aşamasında döner aletlerle, ultrasonik enstrümanlarla, lazer tedavisi ile, ışık ile beyazlatma sırasında, geçici kuron - köprü yapımında ve kompozit restorasyon materyallerinin ışı ile polimerizasyonu sırasında olabilir ${ }^{9-11}$.

Polimerizasyon sırasında rezin kütle içerisinde bir egzotermik reaksiyon meydana gelmekte ve bunun sonucunda ISı açığa çıkmaktadır. Oluşan bu ısının özellikle pulpaya yakın restorasyonlarda pulpada iyatrojenik bir zarara neden olabileceği yapılan çeşitli çalışmalarda gösterilmiştir. Materyalin polimerizasyonu sırasında $43^{\circ} \mathrm{C}-44^{\circ} \mathrm{C}^{\prime} \mathrm{yi}$ aşan Isılarda pulpada istenmeyen etkiler oluşabilmektedir ${ }^{10,14,17}$. Son yıllarda ışık ile polimerizasyon esnasında oluşan ISı artışı dikkat çekmeye başlamıştır.

Bu çalışmanın amacı farklı iki akışkan özellikli kompozit restoratif materyalin iki farklı LED ışık kaynağı ile foto aktivasyonu ve polimerizasyonu sırasında meydana gelen ıSı artışının ölçülerek karşılaştırılması ve pulpada meydana gelebilecek olası zararın tartışılmasıdır.

\section{GEREÇ VE YÖNTEM}

Çalışmada dolgu materyallerini polimerizasyon için yerleştirmek üzere $10 \mathrm{~mm}$ çapında, $2 \mathrm{~mm}$ yüksekliğinde teflon kalıplar hazırlanmıştır. Hazırlanan teflon kalıbın tabanına, dolgu materyaline doğrudan temas edecek biçimde bir termal uç ile bağlantılı dijital termometreden oluşan bir düzenek yerleştirilmiştir.

Dolgu materyali olarak akışkan kompozit Filtek-Ultimate Flowable Restorative (3M ESPE, St Paul, MN, USA) ve SDR (Smart Dentin Replacement Material) ; (Dentsply Caulk, Milford, DE, USA) ve ışık kaynağı olarak da iki farklı LED ışık kaynağı ; Elipar S10 (3M ESPE, St Paul, MN, USA) ve WoodPeckerLEDB (Keju Med.Prod.,Foshan,China) (Tablo 1)

Filtek-Ultimate Flowable Restorative (3M ESPE, St Paul, MN, USA) ,düşük viskoziteli, radyo-opak bir akışkan nano-kompozit materyaldir. Bis-GMA, TEGDMA ve Prokrilat rezinleri içerir. Doldurucu partiküller 0.1-5 mikron büyüklüğündedir. SDR (Smart Dentin Replacement Material) ; (Dentsply Caulk, Milford, DE, USA) düşük viskoziteli, radyo-opak, bulk-fill özellikli bir rezin kompozit materyaldir.

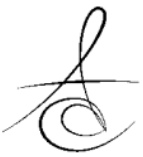


Atatürk Üniv. Diş Hek. Fak. Derg.

J Dent Fac Atatürk Uni

Cilt:28, Sayı:4, Yıl: 2018, Sayfa, 482-486

Tablo 1. Çalışmada kullanılan restoratif materyaller.

\begin{tabular}{|c|c|c|c|c|}
\hline Ürün & Firma & Matriks & Doldurucu & $\begin{array}{l}\text { Doldurucu } \\
\text { Yükü }\end{array}$ \\
\hline $\begin{array}{l}\text { Filtek Ultimate } \\
\text { Flow } 3930 \text { A2 }\end{array}$ & $\begin{array}{l}\text { 3M ESPE, St } \\
\text { Paul, MN, } \\
\text { USA }\end{array}$ & $\begin{array}{l}\text { Bis GMA } \\
\text { TEGDMA }\end{array}$ & $\begin{array}{l}\text { Zirkon/Silika } \\
\text { Ytterbium } \\
\text { trifluorid }\end{array}$ & 65 wt $\%$ \\
\hline $\begin{array}{l}\text { SDR (Smart } \\
\text { Dentin } \\
\text { Replacement) U }\end{array}$ & $\begin{array}{l}\text { Dentsply } \\
\text { Caulk, } \\
\text { Milford, DE, } \\
\text { USA }\end{array}$ & $\begin{array}{l}\text { SDR patentli } \\
\text { Üretan- } \\
\text { Dimetakrilat } \\
\text { Di-metakrilat }\end{array}$ & $\begin{array}{c}\text { Ba-Al-F-B Silikat } \\
\text { cam, Sr-Al-F } \\
\text { Silikat cam }\end{array}$ & 68 wt $\%$ \\
\hline
\end{tabular}

Restorasyon materyallerinin teflon kalıplar içerisine yerleştirildiği andaki polimerizasyon öncesi ISI değeri başlangıç ISı değeri olarak kabul edilmiştir. Materyaller ardından LED ışık kaynağı ile 30 sn süre ile polimerize edilmiştir. 20. sn'nin sonundaki ISı değeri ve 30 sn sonundaki ISI değerleri kaydedilmiştir. 30.sn sonundaki ISI, son ISI olarak kaydedilmiştir. Her bir malzemeden 40'ar örnek hazırlanmış ve oluşan ISI farkları kaydedilmiştir. Toplam 80 örnek üzerinden 320 ISI ölçümü gerçekleştirilmiştir. Kaydedilen başlangıç ISI değerleri ile 20. ve 30.sn'nin sonunda oluşan ISI değerlerinin farkları alınarak istatistiksel analiz yapılmıştır. Çalışmanın istatistiksel analizleri IBM SPSS Statistics 22 programı kullanılarak yapılmıştır.

\section{BULGULAR}

Işık ile polimerizasyonun tamamlandığı 20. ve 30. sn nin sonunda 3M Filtek Ultimate Flow akışkan kompozit örneklerin ISISI:

20.sn sonunda Elipar ile polimerize edildiğinde, $45,43 \pm 2,91^{\circ} \mathrm{C}$; Woodpecker ile polimerize edildiğinde $37,49 \pm 1,81^{\circ} \mathrm{C}$ olarak kaydedilmiştir.

30.sn sonunda ise, Elipar ile polimerize edildiğinde ortalama $47,39 \pm 2,79^{\circ} \mathrm{C}$; Wood-Pecker ile polimerize edildiğinde $38,88 \pm 1,76^{\circ} \mathrm{C}$ olarak kaydedilmiştir.

20. sn nin sonunda SDR restorasyon materyalinden hazırlanan örneklerin ISISI:

Elipar ile polimerize edildiğinde ortalama 40,79 $\pm 0,93{ }^{\circ} \mathrm{C}$; Wood-Pecker ile polimerize edildiğinde 44,0 $\pm 2,5^{\circ} \mathrm{C}$; 30 saniyenin sonunda ise, Elipar ile poli-

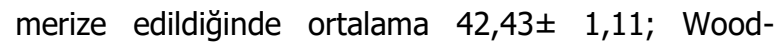
Pecker ile polimerize edildiğinde 45,12 \pm 2,7 olarak kaydedilmiştir.

Başlangıç ISISı ve 20 ve 30. saniyeler sonunda meydana gelen ISı farkı değerlendirildiğinde;

Filtek Flow (3M ESPE) dolgu materyalinin Elipar ışık kaynağı ile polimerizasyonu sırasında başlangıç-ısı farkı ortalaması materyalin Woodpecker ışık cihazı ile
ÖNER ÖZDAŞ ,ZORLU

KARATABAN

polimerizasyonu sırasında ölçülen başlangıç-ıSı farkı ortalamasından istatistiksel olarak anlamlı derecede yüksek bulunmuştur $(p=0,0001)$. Benzer şekilde SDR (Dentsply) -Elipar başlangıç-ıSı farkı ortalaması SDRWoodpecker başlangıç-ıSı farkı ortalamasından istatistiksel olarak anlamlı derecede yüksek bulunmuştur $(p=0,001)$.

Materyaller kendi içlerinde değerlendirildiğinde ise; Filtek Flow dolgu materyalinin Woodpecker ışık kaynağı ile polimerizasyonu sırasında meydana gelen ISI farkı SDR' nin Woodpecker ile polimerizasyonu sırasında ölçülen başlangıç-ısı farkı ortalamasından istatistiksel olarak anlamlı derecede düşük bulunmuştur $(p=0,0001)$.

$\mathrm{Bu}$ durumun aksine, Filtek Ultimate-Flow restorasyon materyalinin Elipar ışık kaynağı ile polimerizasyonu sırasında meydana gelen ISı farkı SDR restorasyon materyalinin Elipar ile polimerizasyonu sırasında ölçülen başlangıç-ıSı farkı ortalamasından istatistiksel olarak anlamlı derecede yüksek bulunmuştur (Tablo 2)

Tablo 2. Dolgu maddelerinin farklı ışık kaynakları ile polimerizasyonları sırasında oluşan ISı farklarının ( $\Delta \mathrm{t})$ karşılaştırııması

\begin{tabular}{|c|c|c|c|c|}
\hline & & \multicolumn{2}{|c|}{ Işık Kaynağı } & \multirow[b]{3}{*}{$\mathbf{p}$} \\
\hline & & Elipar & WoodPecker & \\
\hline $\begin{array}{l}\text { Dolgu } \\
\text { Maddesi }\end{array}$ & Zaman & \multicolumn{2}{|c|}{ Isı Farkı $(\Delta t)$} & \\
\hline \multirow[t]{3}{*}{$\begin{array}{l}\text { 3M Filtek } \\
\text { Ultimate }\end{array}$} & $\begin{array}{r}\text { Başlangıç } \\
-20 \mathrm{sn}\end{array}$ & $19,07 \pm 2,52$ & $12,79 \pm 1,61$ & 0,0001 \\
\hline & $\begin{array}{r}\text { Başlangıç } \\
-30 \mathrm{sn}\end{array}$ & $21,03 \pm 2,39$ & $14,19 \pm 1,42$ & 0,0001 \\
\hline & $\mathbf{p}$ & 0,037 & 0,017 & \\
\hline \multirow{3}{*}{$\begin{array}{l}\text { SDR (Smart } \\
\text { Dentin } \\
\text { Replacement) }\end{array}$} & $\begin{array}{r}\text { Başlangıç } \\
-20 \mathrm{sn}\end{array}$ & $15,95 \pm 0,97$ & $14,08 \pm 1,18$ & 0,0001 \\
\hline & $\begin{array}{r}\text { Başlangıç } \\
-30 \mathrm{sn}\end{array}$ & $17,58 \pm 1,19$ & $15,2 \pm 1,41$ & 0,0001 \\
\hline & p & 0,03 & 0,25 & \\
\hline
\end{tabular}

\section{TARTIŞMA}

Fiziksel, kimyasal ya da biyolojik uyaranlar pulpa içinde oluşabilecek kan akımı bozukluklarına ve pulpada patolojik lezyonların oluşmasına neden olabilmektedir. Diş dokularının preperasyonu sırasında döner aletlerin etkisiyle ve restoratif materyallerin polimerizasyonu sırasında meydana gelen ISı oluşumu bu lezyonların oluşmasında başlıca etkendir. Günümüzde kompozit rezin esaslı restoratif materyallerin polimerizasyonu için ışık kaynakları kullanılmaktadır.

Pek çok çalışma ile kompozit rezinlerin polimerizasyonunda kullanılan ışık kaynaklarının, restoras- 
yonların başarısını doğrudan etkilediği öne sürülmüştü $^{7,8}$. Bu nedenle halojen ışık kaynaklarına alternatif olarak LED, Plazma ark, lazer gibi çeşitli ışı kaynakları geliştirilmiştir. Plazma ark ve lazer ışık kaynaklarının yüksek ISı oluşturmaları ve pahalılıkları dezavantaj oluşturmaktadır ${ }^{17,18}$. LED ışık kaynakları ise uzun ömürlü olmaları, polimerizasyon esnasında ısı oluşturmamaları, polimerizasyon sürelerinin kısa olması nedeniyle tercih edilmektedirler. Çeşitli kaynaklarda LED ışık kaynağı ile polimerizasyon esnasında oluşan ısının halojen ışık kaynağına oranla daha az olduğu bildirilmektedir ${ }^{5}$.Bu nedenle bu çalş̧mada da sıklıkla kullanılan LED ışık kaynakları olan Elipar® ve Woodpecker® tercih edilmiştir.

Zach ve ark. ${ }^{20}$, pulpada oluşabilecek $5,5^{\circ} \mathrm{C}^{\prime}$ den yüksek sıcaklıkların $\% 15-60$ oranında geri dönüşsüz pulpa hasarına neden olduğunu bildirmektedir. Söz konusu çalışmaya göre $16,6^{\circ} \mathrm{Clik}$ bir sıcaklık artışı pulpanın \%100 nekrozuna sebep olmaktadır.

Çalışmamızda da materyalin oda sıcaklığındaki başlangıç ısısı ile ışınlamanın 20. ve 30. saniyesindeki sıcaklık farkları değerlendirilmiştir. En düşük sıcaklık farkının 20. saniyede $12,79^{\circ} \mathrm{C}$, en yüksek sıcaklık farkının ise 30 . saniyede $21,03^{\circ} \mathrm{C}$ olduğu belirlenmiştir.

Yapılan çalışmalarda kavite preparasyon yönteminin, kalan dentin dokusunun kalınlığının, soğutma ve çalışma hızının ve dolgu materyali tipinin çeşitli oranlarda pulpa cevabını etkilediği görülmüştür Özellikle kalan dentin kalınlığının az olduğu $(1.2 \mathrm{~mm})$ derin kavitelerde, pulpanın ısıdan etkilenmesi daha fazla olmaktadır 2,12,15,16.

$\mathrm{Bu}$ çalışmada da $2 \mathrm{~mm}$ kalınlığındaki restorasyon materyalinin üzerinden ışık kaynağı uygulanarak iletilen ISI miktarı belirlenmeye çalışıııı̧ııı.

Geçici restorasyon materyallerinin oluşturduğu ıI farklarının değerlendirildiği bir çalışmada pulpada en az ISı farkını bis-akrilat kompozit içerikli malzemenin oluşturduğu görülmüştür ${ }^{14,16}$.

Bu çalışmada da ışık kaynağının dolgu materyalinin oluşturduğu ısı farkı üzerine doğrudan etki ettiği görülmüştür. Her iki restoratif materyal de Woodpecker ışı cihazı ile daha az ISI farkı oluşturmuştur; ancak Filtek Ultimate Flow akışkan kompozit restoratif materyal her iki ışık cihazı ile de SDR materyaline göre anlamlı derecede yüksek bir ISI absorbe ederek polimerize olmuştur.

Sonuç olarak iki farkı LED ışık kaynağı ile polimerizasyonu sağlanan düşük viskoziteli dolgu maddeleri olan Filtek Ultimate Flow ve SDR'nin polimerizasyonu esnasında oluşan Isı farkı $5.5^{\circ} \mathrm{C}$ den fazladır. Derin kavitelerde, pulpaya yakın restorasyonlarda dişin preparasyon tekniği kadar seçilecek malzeme ve ışık kaynağı da önem taşımaktadır. Pulpaya yakın, derin kavitelerde akışkan kıvamlı dolgu maddelerinin kullanılırken pulpada geri dönüşümsüz hasar bırakabileceği göz önünde bulundurulmalıdır.

Didem ÖNER ÖZDAŞ: ORCID ID: 0000-0002-0112-1539

PInar KIymet KARATABAN: ORCID ID: 0000-0002-20195728

Sevgi ZORLU: ORCID ID: 0000-0003-3435-6833

\section{KAYNAKLAR}

1. Gorgen VA, Guler C. Dişhekimliğinde artık monomerler: bir literatür derlemesi. Medicine Science 2015;4:2024-38.

2. Altıntaş $\mathrm{SH}$, Yöndem I, Tak $\mathrm{O}$, Usumez $A$. Temperature rise during polimerization of three different provisional materials. Clin Oral Investig 2007; 12:283-6.

3. Castelnuovo J, Tjan AHL. Temperature rise in pulpal chamber during fabrication of provisional resinous crowns. J Prosthet Dent 1997;78:5;4426.

4. Knežević A, Tarle Z, Sutalo J, Pichler G, Ristić M. Degree of conversion and temperature rise during polymerization of composite resin samples with blue diodes J Oral Rehabil 2001 Jun;28586-91.

5. Bağlar S, Dallı M, Çolak H, Ercan E, Hamidi MM. İki farkı restoratif materyalin sınıf $\mathrm{V}$ kavitelerdeki mikrosizıntıya etkisi. Cumhuriyet Dental Journal 2010;13:9-14.

6. Çekiç I, Ergün G. Diş hekimliğinde kullanılan görünür ışık kaynakları. GÜ Diş Hek Fak Derg 2007; 24: 131-6.

7. Stahl $F$, Ashworth $S H$, Jandt KD, Mills RW. Light emitting diode (LED) polymerization of dental composites: flexural properties and polymerization potential. Biomaterials 2000; 21:1379-85.

8. Altun $C$, Kabalay U, Güven $G$, Başak F, Akbulut E. Pediatrik Dişhekimliğinde fotoaktivasyon yöntemlerinin restoratif materyalin polimerizasyon büzülmesi üzerine etkileri. Gülhane Tıp Dergisi 2005;47:127-31. 
9. Lloyd $\mathrm{CH}$, Joshi $\mathrm{AE}$, McGlynn E. Temperature rises produced by light sources and composites during curing. Dent Mater 1986;2:170-7.

10. Malmström HS, McCormack SM, Fried D, Featherstone JDB. Effect of $\mathrm{CO}_{2}$ laser on pulpal temperature and surface morphology: an in vitro study. J Dent 2001;29:521-9.

11. Masutani S, Setcos JC, Schnell RJ, Phillips RW. Temperature rise during polymerization of visible light activated resins. Dent Mater 1988;4:174-8.

12. Aydemir H, Taşdemir T, İnan U, Yavuzoğlu $S$, Ünal O. Sistem ısı kaynağının in vitro kullanımında kök yüzeyindeki ıSı değişiklikleri: diş grupları ve preparasyon kalınlığı ile ilişkisi. Ondokuz Mayıs Üniv Diş Hek Fak Derg 2000; 3: 13-6.

13. Hannig $M$, Bott B. In-vitro pulp chamber temperature rise during composite resin polymerization with various light curing sources. Dent Mater 1999; 15: 275-81.

14. Michalakis K, Pissiotis A, Hirayama $H$, Kang K, Kafantaris $\mathrm{N}$. Comparison of temperature increase in the pulp chamber during the polymerization of materials used fort he direct fabrication of provisional restorations. J Prosthet Dent 2006; 96 : 418-23.

15. Schneider LFJ, Cavalcante LMA, Tango RN, Consani S, Sinhoret MAC, Sobrinho LC. Pulp chamber temperature changes during resin composite photoactivation. Braz J Oral Sci 2005; 4: 685-8.

16. Singh MR, Tripathi A, Dhiman CRK, Kumar CD. Intrapulpal thermal changes during direct provisionalization using various autopolymerizing resins: ex-vivo study. AFMS India. 2015;71:31320.

17. Tarle Z,Meniga A, Knezevic A, Sutalo J, Ristic M, Pichler G. Composite conversion and temperature rise using a conventional, plasma arc and an experimental led light curing unit. J Oral Rehabil 2002; 29: 662-7.

18. Kwon TY, Bagheri R, Kim YK, Kim KH, Burrow MF.Cure mechanisms in materials for use in esthetic dentistry. J Invest Clin Dent 2002;3:3-16.
19. Barutcigil C, Ahmetoğlu F, Turgut H, Dayı B, Yalçın M. Düşük polimerizasyon büzülmesi gösteren modern kompozitler ile metakrilat esaslı rezin kompozitin konversiyon oranlarının değerlendirilmesi. Atatürk Üniv Diş Hek Fak Derg 2014; 24 : 39-43.

20. Zach L, Cohen G. Pulp response to externally applied heat. Oral Surg Oral Med Oral Path. 1965;19:515-30.

\section{Yazışma Adresi}

Dr. Öğr. Üyesi Pınar KARATABAN

İstanbul Aydın Üniversitesi,

Diş Hekimliği Fakültesi,

Pedodonti ABD, İstanbul, Türkiye

pkarataban@hotmail.com 